\title{
Terry Labonte Chevrolet Dealer Targets College Student Market
}

Norwood McMillian, (E-mail: N_McMill@uncg.edu), University of North Carolina at Greensboro Stephen R. Lucas, (E-mail: SRLucas@uncg.edu), University of North Carolina at Greensboro Benton E. Miles, (E-mail: BEMiles@uncg.edu), University of North Carolina at Greensboro

\begin{abstract}
This case presents the problem of a new owner of an existing dealership coupled with a move to a new location/new facility within the city. The marketing problem is presented whereby a college marketing class is challenged to create a promotional event on campus to make students aware of the dealership and its location. Additionally, two surveys were administered to gain insight of the college student in regard to the dealership and its products/services. Questions/assignments are posed for students appropriate for a marketing promotions course. The questions/assignments address the goals stated by the manager of the dealership.
\end{abstract}

\section{Introduction}

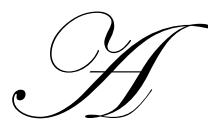

s Scott Rossi, the Sales Manager for the Terry Labonte Chevrolet (TLC) dealership, sat in his office in the dealer's new location on Bridford Parkway, he thought of the progress that has been made over the past two years. In the beginning, Traders Chevrolet was located close to downtown Greensboro on Bessemer Avenue. In a recent turn of events, to meet customer demand and satisfaction, a new facility had been built for the dealership and there was a new owner, Terry Labonte. Labonte is a NASCAR race driver with a well-known name in the area. With the new location (and new facility) and new owner, two questions arose: (1) How would the dealer increase the awareness of General Motors (GM) brands among college students? and (2) How to acquire marketing insights of the college student target market?

During this transition stage, Scott became involved with the General Motors Marketing Internship (GMMI). The GMMI program identifies dealerships throughout the nation to receive special promotional efforts and to involve a university in the local market area. He saw a grand opportunity to create awareness of Terry Labonte Chevrolet (the name that evolved for the dealership) in the community.

\section{The Past and the Future: Traders Chevrolet to Labonte Chevrolet}

This particular Chevrolet dealership (Traders) was first established in the area in the mid-1960s. It was located near downtown Greensboro, 10-15 miles away from the later location on Bridford Parkway. It had the capacity in its showroom to house 33 cars and it was the largest showroom on the East Coast. Indeed, it was an automotive superstore. More than three decades have passed since the inception of Traders. Now, as one views the new facility for the TLC dealership and its new location, it is abundantly clear that this new version of a dealership facility was built on that previous version (superstore) and updated it for the new century.

\section{The Need to Develop an Awareness of the New Location}

To raise the level of awareness in the college student target market regarding the move of the Chevrolet dealership to Bridford Parkway, TLC decided to employ an option of the General Motors Marketing Internship (GMMI) program offered by General Motors. The General Motors Marketing Internship program provides students at a participating university an opportunity to gain business experience while developing and implementing a promotional campaign created by the student interns. General Motors, of course, benefits by the publicity of the cam

Readers with comments or questions are encouraged to contact the authors via email. 
paign. The internship option locally was made viable through its adoption by "Mac" McMillian, a marketing faculty member in the Bryan School of Business and Economics at the University of North Carolina at Greensboro (UNCG). The internship aspect was comprised of UNCG students enrolled in McMillian's marketing classes. The intern plan was administered by the same UNCG faculty member.

\section{EdVenture's Creation of the General Motors Marketing Internship program}

The actual design of the project was solely the responsibility of the college students enrolled in the marketing classes at UNCG. The student interns were to create a marketing firm complete with a business-like environment. To accomplish this task, the internship group was divided into departments and controlled by an upper management team and the heads of each department. The students created the departments that comprised the marketing firm. The conceptualization of the GMMI program embraced the departmental structure and it was the organizer's belief that the objectives of the internship aspect could best be met in this manner.

Since 1990, GM has had specific goals in mind in order to benefit the participating interns of the GMMI program. The goals were to create skills that were much better taught in real-life situations than in classroom settings. Working as a group was a main goal of the creation of the internship. Group/team situations are a part of everyday life in the business world. In the internship, skills such as teamwork, group dynamics, leadership, problem solving, delegation and responsibility, conflict resolution, and communication skills were to be addressed through real-life situations. Other aspects of business such as marketing research, budget and project management, event planning and coordination, and public relations were also skills that the GMMI people deemed necessary to develop in this internship. GMMI wanted these interns to consider the internship as a learning experience that would better acquaint them with the experiences they will encounter in the real world.

General Motors enlisted the expertise of a marketing group, EdVenture Partners (EVP). The EVP created the GMMI program based on the goals stated by GM; EVP manages the GMMI. The main goal of the GMMI program, from the intern viewpoint, was to provide an experiential experience for the interns. EVP implemented the program so that interns would be given a framework of organization and a challenge to use the organizational format to obtain results that would be considered a success in the eyes of GM and the client. In this case, the client and host dealership was Terry Labonte Chevrolet.

The main goals of the GMMI program for TLC were to accomplish the following: (1) increase awareness of the appropriate GM brands among college students, (2) increase awareness of the TLC location and (3) acquire marketing insights of the college student target market.

\section{General Motors Attempts to Target the $X$ and $Y$ Generation}

The main focus of the GMMI program's campaign was to gain insight of the youth market through study of a representative youth market in the particular dealership's geographical area. With the efforts provided through internships such as those at UNCG, valuable marketing data was gathered to provide GM and its dealerships with ways to prepare the Chevrolet workforce to address the youth market. This data also provided positive publicity for the host dealership. The eager marketing interns served as a useful marketing tool.

The GMMI Intern Handbook presents the basis for the internship. In recent years, GM realized that the youth market "niche" was not just a niche, it was a major market. More than 111 million people are in this market (more than $40 \%$ of the total population). When one thinks of the youth market, one must define the youth market. The definitions followed in this report were to place the targeted youth in a $18-35$ year age range. Within this range, the group was further classified into two sub-groups: Generation X and Generation Y. The Generation X population was defined as those in the population age range of $24-35$ while the Generation Y population was defined as the age range from $6-23$. However, the $18-23$ age range was deemed to be the appropriate age range targeted by the UNCG group. 


\section{Youth Brands}

In the GM product line, some vehicles are designed specifically to target the market segment of the " 25 and under" crowd. These brands are termed youth brands. Each division of GM has several vehicles to promote to this market segment. Within the Chevrolet category, vehicles such as the S-10 small pick-up truck and the 2-door Blazer SUV are designed to appeal to the youth market. In the GMC line, the "sister brands" of the Sonoma light truck and the 2-door Jimmy are to be similarly appealing to this market.

\section{Increasing the Awareness of TLC}

Scott realized that if he could not get customers to visit the dealership, he would have to bring the dealership to them. He was quite interested in the benefits of sponsoring a GMMI event on UNCG's campus that would be realized for his dealership. His interest and enthusiasm was quite apparent from the first time he opened the door for the interns to enter the TLC location to the final decision to execute a campus activity.

This was the second year where the UNCG marketing classes were involved in the GMMI program. In the first year, the marketing interns worked on a plan to promote name recognition of the dealership. The promotional campaign of the first year established awareness of the Terry Labonte Chevrolet dealership. The focus for the second year would be directed at the college student market through increased awareness of the TLC dealership and its products and to gain insight of this market segment.

Scott shared with the interns that very little of the profits of TLC were made on the sale of automobiles while the majority of his profits were derived from services that the dealership provided. During this year's campaign, Scott wanted to promote the GM products at TLC and increase his dealership's awareness in the community but also to promote the efficiency and quality of the services offered by the dealership.

As the interns toured his dealership, Scott discussed the various aspects of the services and how much pride the dealership took in maintaining the cleanliness of the service areas. He also stated that with every service the car is washed and presented back to the customer so as to create the perception that the car was better than when it was originally brought to the dealership.

Scott initiated the campaign aspect of getting the potential college student to be a customer of TLC by issuing 300 free oil change coupons to the interns to be given out at a planned event to expose the target market to the TLC cars. During this event, the target market of UNCG students observed the cars on display and participated in activities for prizes. Scott Rossi, the EVP personnel, and the marketing faculty member (Dr. McMillian) viewed the event unfold and marveled at its execution. Scott realized what a wonderful thing the campaign was turning out to be.

Next on the campaign list was to administer a post-event survey. A pre-event survey had already been administered on campus and a measure of the campaign's success would be determined by a comparison of the results of the two surveys. After administering the second survey, the remaining tasks were to analyze the data and to prepare a written report on the results obtained. 


\section{Pre-Event Survey}

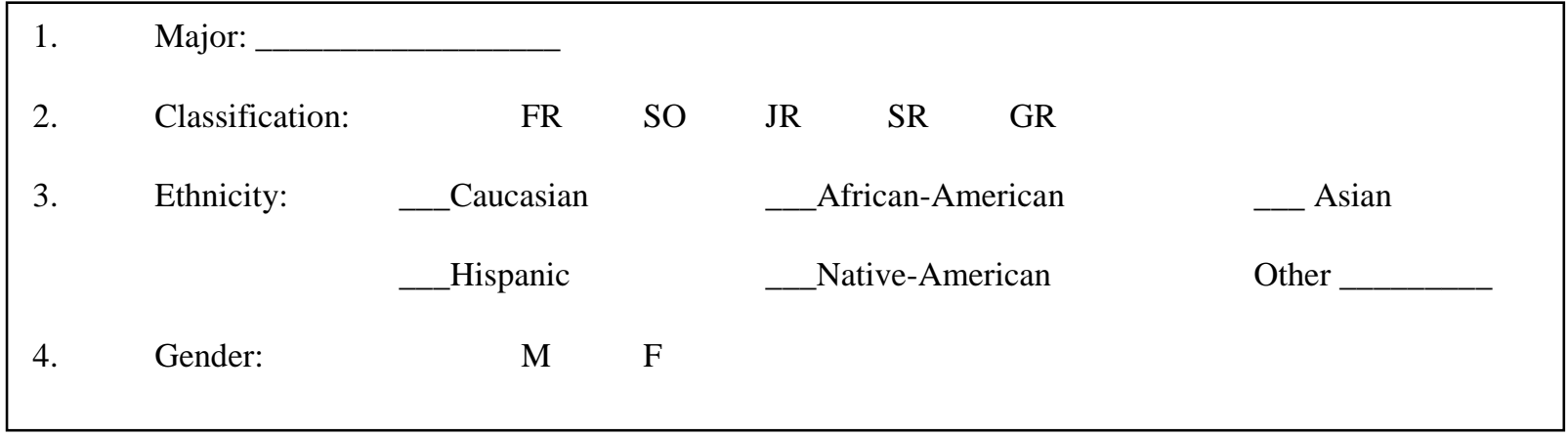

5. Do you intend to purchase or lease a new vehicle within:
__-6 months
_ $7-12$ months $\_1-2$ years
_3-5 years _ _ 5+ years

6. If you were to consider purchasing or leasing a new or used vehicle in the next 5 years, which make and model would you be most likely to consider?
( $1^{\text {st }}$ choice $)$
$\left(2^{\text {nd }}\right.$ choice $)$
( $3^{\text {rd }}$ choice $)$

7. In what price range do you believe your next new vehicle will be? (Check one)
__Less than $\$ 15,000$
$\$ 15,001-\$ 20,000$
_ $\$ 20,001-\$ 25,000$
$\ldots 25,001$ or more

8. How many dealerships would you likely visit before you purchase your next vehicle?

9. Will you use the Internet to learn about new cars? (Check one)
__Definitely
Probably
Possibly
Definitely not

10. Will you use the Internet to purchase a new car? (Check one)
__Definitely
Probably
Possibly
Definitely not

11. Rank the following finance options in order of relative desirability.

Use a scale of 1-6, using each number only once (Most desirable $=1$; Least desirable $=6$ )

Cash back deals (or low down payment allowances

$100 \%$ financing option (no down payment)

Delayed interest or payment schedules

Low percentage rates (APR) on financing

_ L Lower payments through leasing

__ Incentives for special groups (e.g., college grads)

12. Overall, how would you rate the following?

\begin{tabular}{|l|c|c|c|c|c|c|}
\hline & Excellent & Very Good & Good & Fair & Poor & Don't Know \\
\hline Chevrolet & 5 & 4 & 3 & 2 & 1 & 0 \\
\hline Toyota & 5 & 4 & 3 & 2 & 1 & 0 \\
\hline Pontiac & 5 & 4 & 3 & 2 & 1 & 0 \\
\hline Volkswagen & 5 & 4 & 3 & 2 & 2 & 1 \\
\hline Oldsmobile & 5 & 4 & 3 & 2 & 2 & 0 \\
\hline Saturn & 5 & 4 & 3 & 2 & 1 & 0 \\
\hline Nissan & 5 & 4 & 3 & 2 & & 0 \\
\hline Honda & 5 & 4 & 3 & 2 & & 1 \\
\hline GMC & 5 & 4 & 3 & & & 0 \\
\hline
\end{tabular}


13. Have you ever heard of Terry Labonte Chevrolet? Yes No

\section{If your answer is NO, then skip to Question 17}

14. If yes, do you know where it is located? Yes No

15. Have you ever visited the dealership? Yes No

16. Are you aware of its new location? Yes No

17. Circle the radio station that you most frequently listen to.

$\begin{array}{llllllllll}\text { Radio Station: } & 88.5 & 90.1 & 92 & 93 & 94.5 & 98.3 & 97.1 & 98.7 & 99.5 \\ & 100.3 & 102.1 & 104.1 & 107.5 & \text { Other } & & & & \end{array}$

18. Circle the newspaper that you most frequently read.

Newspaper: Archdale-Trinity News High Point Enterprise

News \& Record Winston-Salem Journal

The Thomasville Times Time News

Other

19. Which method of on-campus advertisement attracts you the most?

E-mail

Flyers
Carolinian Spartan Sport News All of the above Other

End of the Pre-Event Survey 


\section{Post-Event Survey}

\begin{tabular}{|c|c|c|c|c|c|c|}
\hline 1. & Major: & & & & & \\
\hline 2. & Classification: & FR & SO & JR & SR & GR \\
\hline 3. & E-mail Address: & & & & & \\
\hline
\end{tabular}

4. Do you intend to purchase or lease a new vehicle within:
_- $0-6$ months
_ 7-12 months _ $1-2$ years
_3-5 years _ _ 5+ years

5. If you were to consider purchasing or leasing a new or used vehicle in the next 5 years, which make and model would you be most likely to consider?
( $1^{\mathrm{st}}$ choice $)$
$\left(2^{\text {nd }}\right.$ choice $)$
$\left(3^{\text {rd }}\right.$ choice $)$

6. In what price range do you believe your next new vehicle will be? (Check one)
__Less than $\$ 15,000$
_ $\$ 15,001-\$ 20,000$
__\$20,001-\$25,000
$\ldots 25,001$ or more

7. How many dealerships would you likely visit before you purchase your next vehicle?

8. Will you use the Internet to learn about new cars? (Check one)
___ Definitely
_. Probably
Possibly
Definitely not

9. Will you use the Internet to purchase a new car? (Check one)

_Definitely _Probably Possibly

Definitely not

10. Rank the following finance options in order of relative desirability.

Use a scale of 1-6, using each number only once (Most desirable $=1$; Least desirable $=6$ )

Cash back deals (or low down payment allowances

$100 \%$ financing option (no down payment)

_ Delayed interest or payment schedules

__ Low percentage rates (APR) on financing

_ Lower payments through leasing

_ Incentives for special groups (e.g., college grads)

11. Overall, how would you rate the following?

\begin{tabular}{|l|c|c|c|c|c|c|}
\hline & Excellent & Very Good & Good & Fair & Poor & Don't Know \\
\hline Chevrolet & 5 & 4 & 3 & 2 & 1 & 0 \\
\hline Toyota & 5 & 4 & 3 & 2 & 1 & 0 \\
\hline Pontiac & 5 & 4 & 3 & 2 & 1 & 0 \\
\hline Volkswagon & 5 & 4 & 3 & 2 & 1 & 0 \\
\hline Oldsmobile & 5 & 4 & 3 & 2 & 1 & 0 \\
\hline Saturn & 5 & 4 & 3 & 2 & 1 & 0 \\
\hline Nissan & 5 & 4 & 3 & 2 & 1 & 0 \\
\hline Honda & 5 & 4 & 3 & 2 & 1 & 0 \\
\hline GMC & 5 & 4 & 3 & 2 & 1 & 0 \\
\hline
\end{tabular}

12. Did you attend the GM promotional event "Pre-Summer Slam II" on Wednesday, April 4, 2001, sponsored by Spartan Solutions at the Fountain? Yes No 
13. Were you aware of the event?

\section{If your answer is NO, then skip to Question 18}

15. If yes, how did you hear about the event? _ Flyers Carolinian Word of mouth Walked into it

16. What do you remember most about the event?

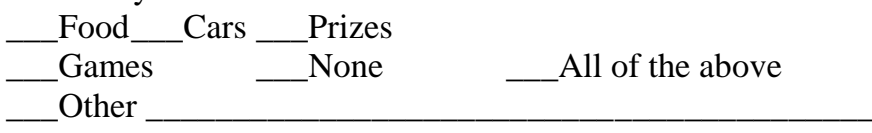

17. How would you rate the event?

_Excellent __Very Good__Average__Below Average __Poor

18. How would you describe your favorite GM car at the event?

$\begin{array}{llll}\text { Sporty _Economical _Exciting _ _ Comfortable _ _ Reliable } & \end{array}$

19. How would you rate the style and performance of Chevrolet vehicles?
_Excellent
__ Very Good
_. Average
_Below Average
_Poor

20. How likely is it that you would consider a Chevrolet for your next vehicle? __Very likely___Somewhat likely___Somewhat unlikely _Very unlikely

21. Have you visited www.spartansolutions01.com? Yes No

22. Have you visited the Web site for Terry Labonte Chevrolet? Yes No

23. Do you know where Terry Labonte Chevrolet is located? Yes No

\section{End of the Post-Event Survey.}

\section{Questions/Assignments:}

1. Critique the sample pre-event and post-event surveys included above.

2. Prepare the two instruments, mentioned above, for administration on your campus.

3. Organize the groups needed in order for your class to facilitate a promotional campaign to address the stated objectives.

4. What problems do you anticipate encountering in carrying out activities to meet the objectives of the campaign?

5. Develop a budget for the entire project to include surveys and promotional activities.

6. Investigate how students can sponsor a promotional event on your campus. Identify the campus contacts and the forms to be submitted, deadlines to adhere to, and any other criteria to be considered.

7. Develop a calendar that will list preferred dates and take into consideration such items as weather, competing events, and place availability.

\section{Endnote}

GMMI Institute Handbook, EdVenture Partners and General Motors Corporation, 2002. 
Notes 